DOI:

\title{
THE PECULIARITIES OF THE USE OF STYLISTIC NOTES IN GENERAL BILINGUAL DICTIONARIES
}

\author{
Abdusalom Mamadnazarov \\ Doctor of Philological Sciences, professor \\ Tajik National University \\ (Dushanbe, Tajikistan) \\ e-mail: abdusalomm@,mail.ru
}

\begin{abstract}
The aim of the article is to the study and analyze the use of stylistic notes or labels in general bilingual dictionaries in Tajik lexicography. The author uses the comparative method to describe the common features and differences in using stylistic labels. As a result, the peculiarities of bilingual dictionaries - Russian-Tajik, Tajik-Russian, English-Tajik and Tajik-English are found in terms of using the stylistic labels. The comparative analysis of the use of stylistic labels in bilingual dictionaries shows that the stylistic labels are used as an important lexicographic device in order to emphasize the stylistic peculiarities of the units of the dictionary. It is noted that bilingual dictionaries use different ways of shortening stylistic notes, the number and the names of stylistic labels are different in different bilingual dictionaries. There is no a generally excepted system of names and types of stylistic labels used in Tajik bilingual dictionaries.
\end{abstract}

Keywords: bilingual lexicography, comparative, stylistic notes, monolingual dictionary

\section{ОСОБЕННОСТИ ИСПОЛЬЗОВАНИЯ СТИЛИСТИЧЕСКИХ ПОМЕТ В ОБЩИХ ДВУЯЗЫЧНЫХ СЛОВАРЯХ}

\author{
Абдусалом Мамадназаров \\ Профессор кафедры английского языка и сопоставительной типологии \\ факультета языков Азии и Европы \\ доктор филологических наук \\ Таджикский национальный университет \\ (Душанбе, Таджикистан) \\ E-mail: abdusalomm@mail.ru; abdusalom.mamadnazarov@gmail.com
}

\begin{abstract}
Аннотация. Целью статьи является изучение и анализ использования стилистических помет в общих двуязычных словарях в таджикской лексикографии. Автор использует сравнительный метод для описания общих черт и различий в использовании стилистических помет. В результате обнаруживаются особенности двуязычных словарей - русскотаджикского, таджикско-русского, англо-таджикского и таджикско-английского с точки зрения использования стилистических помет. Сравнительный анализ использования стилистических помет в двуязычных словарях показывает, что стилистические пометы используются в качестве важного лексикографического приёма, чтобы подчеркнуть стилистические особенности единиц словаря. Отмечается, что двуязычные словари используют разные способы сокращения стилистических помет, количество и названия стилистических помет различны в разных двуязычных словарях. В таджикских двуязычных словарях нет общепринятой системы имен и типов стилистических помет.
\end{abstract}

Ключевые слова: двуязычная лексикография, сравнительный, стилистические пометы, одноязычный словарь

ВВЕДЕНИЕ.Стилистические пометы имеют важное значение в общих двуязычных словарях. В данной статье мы попытаемся проанализировать использование стилистических помет в двуязычных словарях, изданных в таджикской лексикографии в XX и начале XXI вв. «Стилистические пометы (англ. stylistic notes/ marks/ labels; тадж. кайд/ ишораи услуби) указывают на сферу употребления того или иного слова (сnец. - специальное, поэт. - поэтическое и т. п.), отражают характер употребления и бытования слова, его принадлежность к письменной и устной речи (разг. - разговорное, прост. - просторечное и т.п.), указывают на историческую принадлежность (ист. - историческое, арх. - архаическое), на эмоциональную окрашенность (ирон. ироническое, бран. - бранное, шутл. - шутливое, и т. п.) Иногда при заимствованных словах используется пометы указывающие на происхождение слова (араб. - арабское, нем. - немецкое и т. п.)» (Vyalkina 2008: 354).

ОБЗОР ЛИТЕРАТУРЫ. Использованию стилистических помет в лингвистических словарях английского и русского языков посвящены многочисленные исследования современных ученых - лингвистов: П.Н. Денисов (1977), В.А. Звегинцев (1973), Ю.Н. Караулов (1982), В.М. Солнцев (1979), Ю.С. Степанов (1975), А.А. Уфимцева (1968), Д.Н. Шмелев и др. в том числе и специальные исследования Н.М. Несова (2007). В таджикской современной двуязычной лексикографии данная тема исследуется впервые.

По утверждению О.С. Ахмановой, помета - лексикографический приём, состоящий в использовании определённой (установленной) системы сокращенных обозначений и позволяющий расширить объем и разнообразие сведений о включаемых словах без существенного увеличения объема издания (Akhmanova, 2010, 339).

Пометы словарные играют существунную роль в описании заголовочных единиц. «Лексикографическая (словарная) помета - эксплицированное в водной части словаря лексикографическое средство (в форме 
сокращенного слова или словосочетания), с помощью которого читателю сообщается, что соответствующая единица относиться к определённой совокупности однородных в каком-либо отношении единиц или явлений» (Morkovkin 1986: 110).

Словарные пометы при заглавном слове в словарях представлены двумя комплексами: пометами грамматическими и стилистическими с учетом типологически значимых аспектов слова.

Грамматический статус слова складывается на основе его частно-грамматических и общекатегориального значений, а стилистический - с учетом функционально-стилевой и экспрессивностилистической характеристики слова (Nesova 2007: 5). В лингвистической литературе нет единой классификации стилистических помет. Большинство лингвистов не разграничивают группы стилистических помет, а лишь указывают на их значения. Часто стилистические пометы подразделяются на: а) социальностилистические; б) функционально-стилистические; в) функционально-исторические и г) эмоциональноэкспрессивные пометы. Имеются и другие классификации.

МЕТОДЫ ИССЛЕДОВАНИЯ. Основными методами исследования являются: сравнения, типологический анализ с целью выявления и сходства и различия использования стилистических помет в двуязычных лингвистических словарях в таджикской лексикографии.

РЕЗУЛЬТАТЫ И ДИСКУССИЯ. Особое место в современных двуязычных словарях, в том числе в нашем Англо-таджикском (Mamadnazarov 2003; 2015), занимают стилистические пометы. Нам кажется, подчеркивает И.Р. Гальперин, ошибочным мнение некоторых лексикографов, что стилистические пометы нужны, главным образом, в словарях толковых и мало что дают для двуязычных словарей, поскольку последние должны в самих переводах отразить стилистические особенности слова (Galperin 1972: 14). И таджикские и английские читатели должны быть информированы о стилистической особенности каждого слова, и чем подробнее эта информация, тем легче пользоваться словарем.

В двуязычной лексикографии исследуемого периода слова впервые стали снабжаться стилистическими пометами в Таджикско-русском словаре под ред. Е.Н. Павловского и др. (Pavlovskiy et. al., 1946). Здесь мы встречаем такие стилистические пометы как: стих. - стихотворное, $y \mathrm{~cm}$. - устная речь, разг. разговорное, ласк. - ласкательное, бран. - бранное слово, книжн. - книжное и др. Например:

бетимсол книжн. беспримерный (Pavlovskiy, 1946: 74)

доманбарсар бран. бесстыдница (Pavlovskiy, 1946: 171)

барака разг. 1. шестой палец на одной руке; 2. шестипалый (Pavlovskiy 1946: 49)

бандибон $y \mathrm{~cm}$. тюремщик (Pavlovskiy 1946: 48)

В следующем Таджикско-русском словаре, изданном в 1954 г. под редакцией М. Рахими и Л. Успенской была принята новая методика составления словарной статьи. В связи с тем, что большая часть словаря была составлена по типу Таджикско-русского словаря, т. 1, изданного в 1946 г. потребовалась большая работа по перестройке всей структуры словаря. Согласно новой структуре, слова снабжены грамматическим пометами, а также пометы указывающими на область употребления слова (Rahimi and Uspenskaya 1954: 8). В результате количество помет увеличено до 16. В данном словаре добавлены такие стилистические пометы как: пренебр. пренебрежительно, простореч. - просторечие, фам. - фамильярное выражение и т.П., например,

кофиябоф пренебр. рифмоплёт (Rahimi 1954: 491)

И в последнем Таджикско-русском словаре под редакцией Д. Саймиддинова и др. количество стилистических помет (17) почти не изменилось. Данный словарь содержит около 70 тысяч слов и словосочетаний, пословиц и поговорок, фразеологических оборотов таджикского языка с переводом на русский язык и является самым полным когда-либо изданным в таджикской переводной лексикографии. Отличительной чертой данного словаря, с точки зрения использования помет, от словаря Е.Н. Павловского (1946) заключаться в том, что здесь составители решили не указывать на заимствование слов, то есть не были использованы пометы, указывающие на происхождение заимствованных слов, в том числе из арабского, которых в таджикском языке наибольшее число. Все пометы (118 единиц) приведены в разделе «Список условных сокращений» (Saymiddinov, at. al., 2006: 19-21), в том числе стилистические, на русском языке. Например,

авлавият $y \mathrm{~cm}$. 1. первичность; 2. предпочтительность (Saimiddinov 2006: 25)

авон II кн. 1. ист. авон (начальник дворцовой охраны); 2. особа, дама; замужняя женщина (Saimiddinov 2006: 25)

адонашаванда разг. нескончаемый, бесконечный, неиссякаемый (Saimiddinov 2006: 27)

атопош пер. см. атопеша (Saimiddinov 2006, 49)

В русско-таджикских словарях, стилистические пометы впервые можно встретить в словаре А. Дехати и H. Ершова (Dehati and Ershov 1949), где приведен список более 150 условных сокращений, в том числе 17 стилистических помет. Словарь содержит более 45 тысяч слов и словосочетаний русского языка и их эквиваленты в таджикском языке. Слова широко снабжены стилистическими и грамматическим пометами, а также пометами, указывающими на область применения слов. По сравнению с выше приведенных таджикскорусских словарях в данном словаре список помет в разделе «Условные сокращения» приведен на русском и таджикском языках: вульг. - вульгарное выражение - ибораи дагал; ирон. - ироническое выражение - ибораи истехзоомез; пренебр. - пренебрежительно - ифодакунандаи тахкир и т.д. Хотя в словарных статьях стилистические пометы приводятся на русском языке, например,

бай-бай разг. алла, хоб; ложись бай-бай биё, алла кун (Dehati 1949: 27)

барахолка ж простор. бозори кухнафуруши, чайковбозор (Dehati 1949: 29) 
безоблачной прям. и перен. беабр, бегубор, соф, тоза, бегаш, букудрат (Dehati 1949: 29)

болван ... 3. бран. ахмак, аблах, кундзехн, беадаб (Dehati 1949: 43)

Количество стилистических помет увеличено до 22 в последнем Русско-таджикском словаре под редакцией М. Асимова (Asimov, 1985, 17-18). Русско-таджикский словарь М. Асимова является наиболее полный и содержит свыше 72 тыс. слов современного русского литературного языка, словосочетания, идиоматику, пословицы и поговорки, которые снабжены наибольшем количеством помет - более 218 грамматических, специальных и стилистических. Также, как и в словаре А. Дехати в данном словаре список помет в разделе «Условные сокращения» (Ихтисорахои шарти) приведен на русском и таджикском языках: высок. высокого стиля - услуби мутантан; ирон. в ироническом смысле - кинояомез; усm. nоэт. устарелое поэтическое слово - калимаи шоиронаи кухнашуда. В данном словаре можно встретить такие стилистические пометы как: разг. - разговорное слово, бран. - бранное слово, прост. - просторечное слово, шутл. - шутливое слово и др.:

безотцовщина ж прост. и обл. 1. бепадари; бепарастори 2. ятим, бепадар (Асимов, 1985, 53)

белоручка м, ж. разг. нозпарвард(а) (Асимов, 1985, 55)

бесовка ж бран. занаки бадхашм, занаки чанчоли (шатох) (Асимов, 1985, 57)

благоверная ж. разг. шутл. завча, хамсар (Асимов, 1985, 63)

Следует, подчеркнуть, что стилистические пометы, независимо от направления словаря, как в русскотаджикских, так и в таджикско-русских словарях исследуемые нами, даются на русском языке. По нашему мнению, стилистические пометы, как и другие виды помет в русско-таджикских словарях следует дать на таджикском языке, а в таджикско-русских словарях на русском языке.

Стилистические пометы не были использованы в первых небольших англо-таджикских и таджикскоанглийских словарях, изданных, в этот период. В тажикско-английском словаре под названием Standard TajikEnglish Dictionary P.В. и Р.А. Олсонов (Olson and Olson, 2000, iii) также не встречаются стилистические пометы. Впервые стилистические пометы на таджикском языке были использованы в нашем словаре English-Tajik University Dictionary (Mamadnazarov, 2003, 18). Здесь читатель может найти пометы гуфт. - (разговорный), мач. - переносное значение), хурди аз. - ласкательное от.

Наибольшее количество помет (130 помет) в таджикско-английских словарях, изданных в исследуемый период можно встретить в словаре Маматова и др. (Mamatov at. al., v-vi). Авторы используют отличительные лексикографические термины, которые не встречаются в других словарях: 1) domain (область применения, т.е. специальные пометы: - aero. aeronautics - аэронавтика); 2) register (регистр, т.е. стилистические - iron. - ironic - иронический; 3) grammar (грамматические - adv. adverb - наречие), 4) origin. (происхождение - Fr. - French французский) и 5) general (общие - e.g. - for example - например). Все пометы, в том числе стилистические, даны на английском языке, что является отличительной чертой данного словаря.

В данном словаре использовано 36 стилистических помет, которые выделены в разделе Labels and Abbreviations (p. v), в том числе 15 указывающих на заимствования из других языков. Среди наиболее известных и наиболее распространенных стилистических помет такие как: colloq. - разговорный, iron. иронический, lity. - литературный, vulg. - вульгарный. Напрмер,

барало colloq. adv. clearly, distinctly, definitely (Mamatov 2005: 54)

барандохтан $v b$. lity. to throw out, to expel (Mamatov 2005: 53)

Составители словаря также использовали такие стилистические пометы как: abus. - оскорбительный, affec. - нежный стиль, juv. - юношеский, sl. - сленг, жаргон, obs. - устарелый, которые в других таджикскорусских и русско-таджикских словарях не встречаются. Например,

балогардон $a d j$., obs. protective, warding off misfortune or trouble (Mamatov 2005: 52)

В Англо-таджикском словаре П. Джамшедова и Т. Рози (Jamshedov and Rosie, 2008: 19-20) также слова снабжены стилистическими пометами. Особенно обращается внимание на происхождение заимствованных слов не только из арабского, латинского, греческого, но и других языков. Например, выделяются слова, заимствованные из таких языков как: хин. - хинди, ирл. - ирландский, анг-хинд. - англо-индийского происхождения и т.д.

В Таджикско-английском словаре П. Джамшедова (Jamshedov 2008: 32), который описывает более 60 тысяч слов и выражение, слова также снабжены стилистическими пометами, хотя в структуре словаря не наблюдается специального раздела со списком помет или сокращений использованные в словаре. Например,

алас-алас coll. to carry out the "alas" ceremony (Jamshedov 2008: 45)

амд lit. intention, goal (Jamshedov 2008: 48)

apш obs. throne; sky (Jamshedov 2008: 57)

Отличительной чертой данного словаря от таджикско-русских словарей, является то, что пометы приведены на английском языке (см. выше приведённые примеры), так как данный таджикско-английский словарь, в основном, предназначен для иностранцев, чей родной язык является английским.

В последнем издании нашего Англо-таджикского словаря (Mamadnazarov, 2015, 24-25) слова снабжены наибольшим количеством стилистических помет. Здесь читатель может найти такие стилистические пометы, как: амер. - американский, лот. - латинский, указывающие на происхождение слов; адаб. - литературный, гуфm. - разговорный), даг. - грубый, жар. - жаргонный, указывающие на принадлежность к определенной речи; шоир. поэтический, шух. - шутливый и т.д. Всего слова данного словаря снабжены более 30 стилистическими пометами, которые дают более подробную стилистическую характеристику слова, тем самым 
намного облегчают задачи пользователей словаря. Например:

salespeople [эse $\forall$ lzpi:pl] n pl амер. фурушандањо (Mamadnazarov 2015: 707)

saphead [s@phed] $n$ гуфm. одами ахмаќ, нофахм, бешуур. (Mamadnazarov 2015: 709)

seafarer [эsi:fEərə] $n$ шоир. дарёнавард, бахрнавард, маллох (Mamadnazarov 2015: 719)

spook [spu:k] n шуx. рух, хаёлот, шабах, сиёхи. (Mamadnazarov 2015: 777)

simile [эs $\forall \mathrm{m} \forall \mathrm{l} \forall]$ n адаб. ташбех, санъати ташбех, истиора (Mamadnazarov, 2015: 745)

Необходимо особенно остановиться на помете амер., указывающей на американский вариант английского языка. Большинство лингвистов сегодняшнего дня придерживаются мнения о равноценности двух вариантов, т.е. американский вариант уже не рассматривается как «побочный» по отношению к британскому.

В таджикской двуязычной лексикографии, в первых небольших словарях американизмы никак не выделялись. Конечно, разграничение британских и американских единиц не могло быть проведено с абсолютной точностью, так как в реальной речевой практике граница между ними подвижна, и в некоторых случаях, весьма условна. Даже словари, изданные в англоязычных странах, иногда сообщают противоречивые друг другу сведения на этот счет. Однако, по мере возможности было сочтено необходимым проводить такое разграничение, ибо смещение единиц из разных вариантов английского языка стало, к сожалению, типичной ошибкой переводчиков и изучающих язык.

Как известно, словарный состав английского языка, равно как и таджикского, представляет собой весьма неоднородную массу, классификация которой всегда является ориентировочной и приближенной. Словарь языка состоит из двух пластов слов: признанный литературный пласт лексики и нелитературный пласт.

Общепризнанный литературный пласт лексики современного английского языка, по мнению многих лингвистов, в том числе И.Р. Гальперина, распадается на три основных слоя: 1) нейтральная лексика, которая включает основную массу слов лексической системы; 2) литературно-книжная лексика общего характера и 3 ) разговорная лексика общего характера. Нейтральная лексика в языке никакими стилистическими пометами не сопровождается. Остальная лексика имеет соответствующие пометы (Galperin 1972: 15).

В свою очередь, литературно-книжная лексика современного английского языка может быть разделена на два слоя: общая литературно-книжная лексика, о которой речь шла выше, и которая входить составной частью в общепризнанный литературный пласт слов (Standard English), и специальная литературно-книжная лексика.

Эта нелитературная разговорная лексика неустойчива по своей природе. Она мало подвергается письменной фиксации и не всегда доступна исследованию. Тем не менее, эта лексика, во многих случаях является источником пополнения и развития словарного состава языка. Здесь тоже выделяются несколько групп слов, имеющих свое стилистическое лицо: профессионализмы, диалектизмы, просторечия, жаргонизмы, вульгаризмы и др.

Ниже будут рассмотрены некоторые группы и слои лексики, трактовка которых очень противоречива в разных монографиях и словарях.

Задачи стилистических помет не ограничиваются только стилистической характеристикой слова: они дают ещё дополнительную информацию в возможностях словоупотребления и более глубоко раскрывают смысловую структуру слова.

Анализ лексикографических работ исследуемого периода показывает, что стилистические пометы в двуязычной таджикской лексикографии используются как важный лексикографический приём для того, чтобы указывать на стилистические свойства разъясняемой или переводимой словарной единицы. Однако, как и в случае с грамматическими пометами, нет единой системы стилистических помет. Наблюдается разнобой в использовании стилистических помет. Используются различные сокращения для обозначения одних и тех же помет. Количество и наименование стилистических помет в разных словарях разное. Составители лексикографических справочников предпочитают подчеркивать разные стилистические свойства лексики в своих словарях. Все стилистические пометы, независимо от авторов и направления языков, графически оформлены курсивным шрифтом.

Использования стилистических помет является также очень важным лексикографическим приемом, позволяющим расширить объем и разнообразие сведений о включаемых словах в словарях без существенного увеличения объема издания. С другой стороны, на данном этапе развития двуязычной лексикографии, необходимо разработать единую систему стилистических и грамматических помет, как родного, так и изучаемого иностранного языков.

ЗАКЛЮЧЕНИЕ. По результатам сравнительного анализа использования стилистических помет в переводных словарях в таджикской двуязычной лексикографии можно сделать некоторые выводы:

Выделяя стилистическая окраска слов в общих переводных двуязычных словарях, авторы предпочитают очень экономно пользоваться стилистическими пометами.

Сравнивая данные современных двуязычных словарях, можно легко обнаружить, что стилистические особенности выражаются в эмоциональной окраске слова, обусловленной сферой его употребления, а также имеющейся качественной характеристикой. Стилистические пометы в основном используются для указания на особенности употребления лексических единиц.

Сравнительный анализ исползования стилистических помет свидетельствует о том, что стилистические пометы так же, как и грамматические пометы, сокращаются в двуязычных словарях различным образом. 
Например: - книжное слово - книжн., кн., прямое значение - прям., пр., просторечие - простор, прост., поговорка - погов., пог., указательное местоимение - указат., указ., прошедшее время - прош., прош. вр., глагол глаг., гл., и т.д. что свидетельствует о не разработанности или не соблюдения единых принципов сокращения помет. Большинство лексикографов приводят список помет в специальном разделе в водной части словаря.

Необходимо разработать, в таджикской двуязычной лексикографии единые правила сокращения стилистических помет с тем, чтобы все лексикографы могли их использовать как для сокращения объёма словаря, так и для указания на различные особенности лексических единиц.

\section{LIST OF REFERENCES}

Akhmanova O.S. (2010). Slovar' lingvisticheskikh terminov [A Dictionary of Linguistic Terms]. Moskva: Librikom.

Galperin I.R. (1972). Vvedenie [Introduction]. Bolshoi English-Russian Dictionary. Moskva: Russkiy yazik, 10-19.

Jamshedov P. (2008). Tajik-English Dictionary. Dushanbe, Ejad.

Jamshedov P., Rosie T. (2005) English-Tajik Dictionary. Dushanbe: Ejad.

Mamadnazarov A. (2015). English-Tajik Dictionary (3rd ed.). Dushanbe: Er-graph.

Mamadnazarov A. (2003). English-Tajik University Dictionary. Dushanbe: Nodir.

Mamadnazarov A. (2016). Stanovlenie i razvitiya tadzhikskoy perevodnoy liksikographii v XX i nachala XXI vv. [The Formation and Development of Tajik Translation Lexicography in the XX and the Beginning of XXI Centuries].

Mamatov J., Harrell, S.J., Kehoe, K., Khodjibaev K. (2005). Tajik-English Dictionary. USA: Dunvoody Press.

Morkovkin V.V. (1986). O bazavom leksikograficheskom znanii // Uchebniki i slovari v sisteme sredstv obucheniya russkomu yaziku kak inostrannogo [About the basic lexicographic knowledge]. Moskva.

Nesova N.M. (2007). Grammaticheskie i stilisticheskie pometi v tolkovikh slovaryakh russkogo i angliyskogo yazikov [Grammatical and Stylistic Notes in General Russian and English Dictionaries]. Avtoreferat dissertatsii. Moscow.

Olson, R.A. Olson, R.B. (2000). Standard Tajik-English Dictionary. Bishkek: Star Publications.

Russian-Tajik Dictionary (1985). Ed. Asimov M.S. Moskva: Russkiy yazik.

Russian-Tajik Dictionary (1949). Ed. by A.P. Dehati and N.N. Ershov. Moscow-Stalinabad: Gosudarstvenoe izdatelstvo inostrannikh i natsionalinikh slovarey.

Tajik-Russian Dictionary (2006). Ed. by D. Saymiddinov, S.D. Kholmatova, S. Karimov. Dushanbe: Donish.

Tajik-Russian Dictionary. Ed. by Pavlovskiy E.N., Bertels, E.E. J. Ikromi J. and Jalil J. (1946). Vol. 1 (A-O). Stalinabad-Tashkent.

Tajik-Russian Dictionary. Ed. by Rakhimi M. and Uspenskaya L.V. (1954). Moskva: Gosudarstvenoe izdatelstvo inostrannikh i natsionalinikh slovarey.

Vyalkina L.V. (2008). Pometa [Label]. Enciklopediya. Russkiy yazik [Encyclopedia. Russian Language]. Moskva. Bokshaya Rossiyskaya Enciklopediya.

\section{For citation:}

Mamadnazarov, A. (2019) THE PECULIARITIES OF THE USE OF STYLISTIC NOTES IN GENERAL BILINGUAL DICTIONARIES. International Scientific-Pedagogical Organization of Philologists “WEST-EAST" (ISPOP). Scientific Journal WEST-EAST. Vol 1/1 N1 (October, 2019). pp. 42-46. doi:

\section{Для цитирования:}

Мамадназаров, А. (2019) ОСОБЕННОСТИ ИСПОЛЬЗОВАНИЯ СТИЛИСТИЧЕСКИХ ПОМЕТ В ОБЩИХ ДВУЯЗЫЧНЫХ СЛОВАРЯХ // International Scientific-Pedagogical Organization of Philologists "WEST-EAST" (ISPOP) . Scientific Journal WEST-EAST. Vol 1/1 N1 (October, 2019). C. 42-46. doi:

Information about the author: Abdusalom Mamadnazarov - Doctor of Philological Sciences, Professor, Department of English Language and Comparative Typology, Faculty of Languages of Asia and Europe,, Tajik National University, Dushanbe, Tajikistan e-mail: abdusalomm@mail.ru

Сведения об авторе: Абдусалом Мамадназаров - доктор филологических наук, профессор кафедры английского языка и сопоставительной типологии факультета языков Азии и Европы, Таджикский национальный университет, Душанбе, Таджикистан

E-mail: abdusalomm@mail.ru; abdusalom.mamadnazarov@gmail.com 